\title{
A Review on COVID-19 related research in leading information systems journals
}

\author{
Yuming He, Old Dominion University,yhe004@odu.edu \\ Wenzhuo li, Old Dominion University,wlixx005@odu.edu \\ Xin Tian, Kennesaw State University, xtian2@kennesaw.edu \\ Yunfei Xing, Central China Normal University,xingyf@mail.ccnu.edu.cn
}

\begin{abstract}
To identify the key challenges, issues and opportunities affecting individuals, organizations, and society on coping with COVID-19, we reviewed extant research related to the COVID-19 pandemic in the leading information systems journals. Six major research themes and representative literature for each theme are identified by content analysis. The six major research themes include digital transformation, data visualization and artificial intelligence, infodemic and cybersecurity, IT governance, digital divide, and IS research direction in the post-pandemic period. Moreover, we discussed the challenges, current research, and opportunities related to each of the themes. The review provides a snapshot of IS literature on the COVID-19 pandemic and can enable scholars to evaluate possible opportunities for conducting research and development activities related to the pandemic.
\end{abstract}

Keywords: pandemic, information technology, data privacy, digitalization, transformation, inequity, digital divide, COVID-19

\section{Introduction}

The COVID-19 pandemic has profound impacts on the world and generated a strong demand for technology to mitigate the adverse effects of COVID-19 on people, public health, society, and the economy (O'Leary, 2020). There is no doubt that technology plays a critical role in mitigating the challenges and hardships people and society encounter. While technology is essential in tackling the COVID-19 pandemic, the behavioral, societal and organizational aspects of technologies and their use are considered necessary to fight against the pandemic. Many information systems (IS) researchers contributed their knowledge and expertise to provide insights, experiences, ideas and recommendations against the COVID-19 pandemic. Many COVID-19 related articles have been published in the IS journals. These articles explored the pandemic from diverse perspectives, including technology, behavioral, temporal, societal, and organizational aspects (Ågerfalk, Conboy, \& Myers, 2020). However, the widespread comment and perspectives amongst academics do not have a very fixed format; organizations and people can have many ways to design their operational strategies. Given the increasing number of publications in this area and the heterogeneity in design, implementation, and insight, the resulting strategy will be highly diverse. Thus, there is a need to conduct a systematic literature review of these articles to provide an up to date review summarizing the key research areas or issues, and contributions made by IS researchers in the fight against COVID-19, and to synthesize what is known about this topic including recommendations and future research directions from IS researchers to address the challenges caused by the pandemic. 


\section{Issues in Information Systems}

Volume 22, Issue 4, pp. 93-109, 2021

The main objective of this paper is to share our synthesis of relevant COVID-19 research in the leading IS journals. Thus, we hope to provide a snapshot of IS literature on the COVID-19 pandemic and enable IS scholars to better understand the current research status in this area. In addition, based on the examination of existing studies, this paper also suggests ideas to guide future research.

The remainder of this paper is organized as follows. In the methodology section, we describe the research methodology used for this study. Results from the systematic literature review are presented in the results section. In the discussion section, we discuss findings from the results of the study; highlight some of the critical challenges; recommendations and identify future directions for IS research. At last, we conclude the paper and highlight potential areas for future research and investigation in the conclusion section.

\section{Methodology}

To understand the IS scholar's perspectives, insights, and efforts to tackle the COVID-19 pandemic, we choose the bibliographic analysis method. We selected fourteen leading information system journals at the $\mathrm{A}^{*}$ level listed in the ABDC (AUSTRALIAN BUSINESS DEANS COUNCIL) Journal Quality List (see Table 1) to be the data source for our study. The comprehensive nature of the ABDC Journal Quality List makes it a key ranking list for business schools worldwide to judge research quality across programs (Glover, 2016).

\section{Search Strategy and Selection Criteria}

This paper follows a fundamental bibliographic research procedure (Tranfield et al., 2003; Webster \& Watson, 2020) to select and filter the extant literature. The detailed process of article screening is shown in the following figure (Fig. 1).

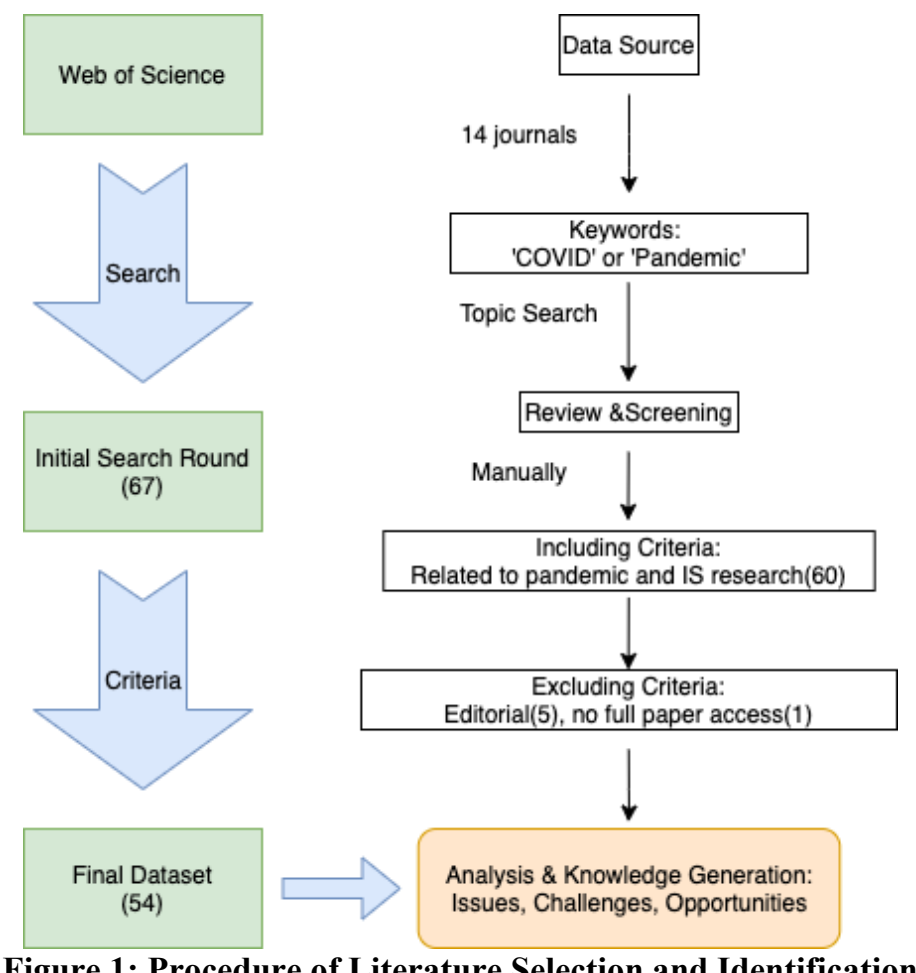




\section{Issues in Information Systems}

Volume 22, Issue 4, pp. 93-109, 2021

Across Web of Science 'All Databases', we used two keywords: 'Pandemic' and 'COVID', to filter potentially relevant articles. The initial search was implemented on May 27, 2021, and we found 67 articles by keyword search. However, some irrelevant or unqualified articles may be selected. Thus, two independent researchers manually reviewed each of the selected article's titles, abstracts, and keywords in detail to remove those papers that included 'pandemic' but were irrelevant to the COVID-19 research under investigation. Letters to the editor, short communications, and other editorial notes that were not subject to the rigorous peer review process were also excluded from our data set. In order to keep rigorousness, we also excluded one paper that we were not able to get full access to despite many attempts.

As a result, 54 articles were included in the final data set for review. Two independent researchers did a content analysis of the full text of these articles and discussed the discrepancy whenever there are questions or confusion. Among the 54 papers, only 22 articles could be genuinely labeled as "original research" which conducted empirical studies or theory development. The remaining 32 articles are opinion papers. Due to the contagious nature of the coronavirus, there are many challenges for researchers to conduct empirical research and collect primary data quickly. Thus, many opinion papers were published to express researchers' thoughts and share their perspectives and suggestions.

\section{Results}

We found that 6 out of the 14 leading IS journals published at least a paper about COVID-19 as of May 25, 2021 (See Table 1). Among the six journals, IJIM and EJIS published 24 and 21 COVID-19 related articles respectively, since both journals have published a special issue about COVID-19 research. It is with mentioning that IJIM published many editorial or opinion papers on COVID-19. The top-ranked IS journals including MISQ and ISR have not published a single research paper on COVID-19 yet. This may be because of their long publication cycle, although they may have papers in the pipeline. 


\section{Issues in Information Systems}

Volume 22, Issue 4, pp. 93-109, 2021

Table 1: Fourteen A* IS journals in the ABDC journal list (in alphabetical order)

\begin{tabular}{|c|c|c|}
\hline $\begin{array}{c}\text { NU } \\
\text { MBE } \\
R\end{array}$ & JOURNAL NAME & RELEVANT COVID-19 ARTICLES \\
\hline $\mathbf{1}$ & ACM TRANSACTIONS ON COMPUTER-HUMAN & 0 \\
\hline $\mathbf{2}$ & INTERACTION (TOCHI) & 1 \\
\hline $\mathbf{3}$ & EUROPEAN JOURNAL OF INFORMATION SYSTEMS (EJIS) & 21 \\
\hline $\mathbf{4}$ & INFORMATION \& MANAGEMENT (I\&M) & 0 \\
\hline $\mathbf{5}$ & INFORMATION AND ORGANIZATION (I\&O) & 6 \\
\hline $\mathbf{6}$ & INFORMATION SYSTEMS JOURNAL (ISJ) & 0 \\
\hline $\mathbf{7}$ & INFORMATION SYSTEMS RESEARCH (ISR) & 0 \\
\hline $\mathbf{8}$ & INTERNATIONAL JOURNAL OF INFORMATION & 24 \\
\hline $\mathbf{9}$ & MANAGEMENT (IJIM) & 1 \\
\hline $\mathbf{1 0}$ & JOURNAL OF MANAGEMENT INFORMATION SYSTEMS & 0 \\
\hline $\mathbf{1 1}$ & JOURNAL OF STRATEGIC INFORMATION SYSTEMS (JSIS) & 0 \\
\hline $\mathbf{1 2}$ & JOURNAL OF THE ASSOCIATION FOR INFORMATION & 1 \\
\hline $\mathbf{1 3}$ & SCIENCE AND TECHNOLOGY (JASIST) & 0 \\
\hline $\mathbf{1 4}$ & JOURNAL OF THE ASSOCIATION FOR INFORMATION & 0 \\
\hline & SYSTEMS (JAIS) & \\
\hline
\end{tabular}

Based on the selected articles, we did a content analysis and developed a table (Table 2.) to show the distribution of key research themes. Six key research themes were identified from our data set: (a) Digital transformation, (b) Data visualization and artificial intelligence (AI), (c) Infodemic and cybersecurity, (d) IT governance, (e) Digital divide, and (f) IS research direction in the post-pandemic period. 


\section{Issues in Information Systems}

Volume 22, Issue 4, pp. 93-109, 2021

Table 2. List of Articles Categorized by Main Research Themes

\begin{tabular}{|c|c|c|}
\hline Research Themes & Focus & Relevant Articles \\
\hline Digital transformation & $\begin{array}{l}\text { Organizations' resilience, } \\
\text { remote collaborative } \\
\text { work and education }\end{array}$ & $\begin{array}{l}\text { Carillo et al., (2021); Carroll \& Conboy (2020); Carugati } \\
\text { et al. (2020); Chatterjee et al. (2021); De' et al. (2020); } \\
\text { Grover \& Sabherwal(2020); Hafermalz \& Riemer (2021); } \\
\text { Iivari et al. (2020); Lin et al. (2020); Majchrzak \& } \\
\text { Shepherd (2021); Papadopoulos et al. } \\
\text { (2020);Papagiannidis et al. (2020); Sakurai \& Chughtai } \\
\text { (2020); Whillans et al. (2021); Westmattelmann et al. } \\
\text { (2021) }\end{array}$ \\
\hline $\begin{array}{l}\text { Data visualization and } \\
\text { artificial intelligence }\end{array}$ & $\begin{array}{l}\text { Data transparency, } \\
\text { visualization and AI- } \\
\text { powered management }\end{array}$ & $\begin{array}{l}\text { Adam et al., (2020); Bae et al. (2021); Coombs (2020); } \\
\text { Pietz et al., (2020); Leonardi et al. (2021); Mirbabaie et } \\
\text { al. (2020); Rao et al. (2020); Recker (2021); Sipior, } \\
\text { (2020) }\end{array}$ \\
\hline $\begin{array}{l}\text { Infodemic and } \\
\text { cybersecurity }\end{array}$ & $\begin{array}{l}\text { Misinformation, privacy } \\
\text { protection and } \\
\text { cybersecurity }\end{array}$ & $\begin{array}{l}\text { Bunker (2020); Laato et al. (2020); Oliphant (2021); } \\
\text { Prommegger et al. (2021); Shirish et al. (2021); Naidoo } \\
(2020)\end{array}$ \\
\hline IT governance & $\begin{array}{l}\text { Tracing app, IT } \\
\text { infrastructure and policy } \\
\text { management }\end{array}$ & $\begin{array}{l}\text { Fahey \& Hino (2020); Faraj et al. (2021); Leclercq- } \\
\text { Vandelannoitte \& Aroles (2020); Lee (2020); Riemer et } \\
\text { al. (2020); Rowe (2020); Rowe et al. (2020); } \\
\text { Urbaczewski \& Trang et al. (2020); Zilber \& Goodman } \\
\text { (2021); }\end{array}$ \\
\hline Digital divide & $\begin{array}{l}\text { Inequity, bullying and } \\
\text { access barriers }\end{array}$ & $\begin{array}{l}\text { Barnes (2020); Fletcher \& Griffiths (2020); Marabelli et } \\
\text { al.(2021); Pan et al. (2020); Parra et al. (2021); Zheng \& } \\
\text { Walsham (2021); }\end{array}$ \\
\hline $\begin{array}{l}\text { IS research direction in } \\
\text { the post-pandemic } \\
\text { period }\end{array}$ & $\begin{array}{l}\text { Lessons learned, } \\
\text { challenge and future } \\
\text { opportunity }\end{array}$ & $\begin{array}{l}\text { Doyle \& Conboy (2020); He et al. (2021); Henningsson } \\
\text { et al. (2021); Pan \& Zhang (2020); Pee et al. (2021); Sein } \\
\text { (2020); Venkatesh (2020); }\end{array}$ \\
\hline
\end{tabular}

It should be noted that there is substantially overlapping in the 54 selected papers amid these six research themes. Quite a few papers discussed more than one theme and showed breadth in scope. A variety of research methodologies including quantitative method, qualitative method and mixed methods have been explored by researchers for COVID-19 research at micro-and/or macro-Level. For example, Shirish et al. (2021) examined the relationships of "mobile connectivity" and "freedom" (economic, political, and media) with fake news propensity at the country level by using a dataset comprising 72 countries generated by combining six independent cross-country data sources. In contrast, Waizenegger et al. (2020) interviewed 29 knowledge workers about their experiences of team collaboration and enforced working from home during COVID-19.

\section{Digital transformation}

The COVID-19 pandemic has put a lot of pressure on many industries where firms struggle to resume their business operation. Temporal lockdowns around the globe led to severe disruptions of everyday business activities and uncertainties for both supply and demand. People and organizations worldwide have to adapt to new ways of working and living through increased digitalization (De' et al., 2020). There is a saying, "Don't let a crisis go to waste". Framing the interplay between changes caused by the pandemic, economic forces and digitalization is an important step (Grover \& Sabherwal, 2020). Many articles have explored the direction of digital transformation and how people view and understand this new normal. 


\section{Issues in Information Systems}

Volume 22, Issue 4, pp. 93-109, 2021

\section{$\underline{\text { Telework research in information systems }}$}

Different from conventional telework, many employees were forced to work at home during the pandemic. Many organizations have been forced to rethink their business models to adapt to the realities posed by the COVID-19 pandemic. The research presented by Carroll and Conboy (2020) explores the need for practical implementation and integrating or adapting the reasonable practices and associated technology in the new workplace context. Also, teleworkers often had to deal with exacerbated professional and personal time balance issues and were forced to adjust their behaviors to adapt to the new work situation. Hafermalz \& Riemer (2021) presented that team communication, such as talking, learning, sharing, and positioning, which together creates belonging relates to the performance of work are interrupted; Professional isolation, telework environment, workload increase, and stress are the dominant crisis-specific factors (Carillo et al., 2021). On the other hand, Whillans et al. (2021) demonstrated that adjustments to enact in the virtual environment successfully require several core activities (task, process, and relationship interactions) mediated by digital technologies. Future research is needed to study the policy and practices to maximize the positive outcomes and minimize the adverse outcomes of telework.

\section{Online education research in information systems}

The COVID-19 pandemic has suddenly forced schools and educators to engage in a rapid digital transformation for teaching and learning. Iivari, Sharma, and Ventä-Olkkonen (2020) empirically studied the inherent tensions stemming from the digital divide and possible barriers reported by educators. Moreover, not all teachers and students are in an equal position to show great resilience and perseverance in responding to the challenge. Researchers should consider how to more effectively manage, deliver and facilitate teaching and learning across all levels of education in the virtual environment. Also, the model of IT adoption in teaching-related practices under crisis should be very different from the traditional ones, Carugati et al. (2020) proposed a model of IT exploration/exploitation based on qualitative data from education institutions and their responses. A recent special section published in Communications of the Association for Information Systems includes more than 20 articles on COVID-19, learning, pedagogy and education systems, which are good reference resources for conducting research in this area.

\section{Resilience capability and business agility}

Given the extreme challenges due to COVID-19, organizations need to be resilient and agile to encounter the adverse effects of this pandemic. The study by Chatterjee et al., (2021) illustrated that developing a compassionate organizational workplace can yield varied benefits for organizations to keep resilience. The fact that wild spread suffering by crises can be alleviated by the creation of 'compassionate ventures' is documented (Majchrzak \& Shepherd, 2021), as crowd-based digital innovations can help transparently share resources. The article by Lin et al. (2020) presented empirical evidence on how e-commerce capability can help agricultural firms ambidextrous by enabling market capitalizing agility and operational adjustment agility. Information systems can foster the resilience of people and organizations by strengthening their adaptation to uncertainty, enabling a transition towards a new normal(Sakurai \& Chughtai, 2020). The articles by Papagiannidis, Harris, and Morton (2020) and Papadopoulos, Baltas, and Balta (2020) discussed how organizations could be more prepared for future pandemics by utilizing information technologies to minimize complexity to business continuity. In the field of sports, Westmattelmann et al. (2021) examined the distinctiveness of sports and eSport by interviewing professional cyclists and found the positive role of virtual sport to help master pandemics. 


\section{Issues in Information Systems}

Volume 22, Issue 4, pp. 93-109, 2021

\section{Data visualization and AI}

Data visualizations and prediction models became critical for guiding practical actions, such as social distancing, widespread testing and contact tracing to minimize better the spread of disease (Pietz et al., 2020, Recker, 2021, Leonardi et al., 2021). Displaying crowding information can encourage physical distancing without restricting users' freedom of choice (Adam et al., 2020). The important role of social media information was examined by Bae et al. (2021), which shows that the big data from social media incorporated with the SEIR model can improve forecasts of COVID-19 infections. A similar study by Rao et al. (2020) and Mirbabaie et al. (2020) demonstrated that communicating emergency information to the public via social media is critical for crisis management, specifically for alarming, establishing reassurance that reduces social media distrust and facilitates sense-making. The rapid spread of the COVID-19 has increased the focus on automation technologies and AI solutions. The research by Coombs (2020) identifies the role of AI in increasing levels of automation and the constraints on AI adoption such as big data availability and reliability, task complexity and high availability of human workers. Since there is a surge in the exploration and use of AI, the development and deployment of AI applications should be managed carefully to deal with biased output, unexpected results, and diversity in team membership (Sipior, 2020). Although big data and emerging technologies are considered as powerful means to facilitate the development and sustainability of organizations and society, the dark side of uncontrolled information leakage shouldn't be neglected.

\section{Infodemic and Cybersecurity}

The rapid surge of fake news, misinformation, and disinformation circulating on the Internet has caused the so-called "infodemic" and limited information researchers to effectively utilize user-generated content (Bunker, 2020). The study by Oliphant (2021) investigated the most influential factors regarding people's social identities and social power by using the concept of epistemic injustice. Similarly, to better understand the factors contributing to the national-wide spread of fake news, Shirish et al. (2021) explored the relationships between "mobile connectivity" with "freedom" and highlighted the necessity for governments to educate people to follow authentic news and invest in tools for identifying misinformation and improving online accountability; Laato et al. (2020) suggests that unverified information sharing most likely happens when a person is in a status of information overload. In this case, data collection becomes an extreme challenge as social distance, physical isolation, and misinformation for the researchers. This change gives significant threats to traditional research, but it also fosters numerous opportunities to study new events by examining the new data sources (Prommegger et al., 2021). On the other hand, remote working environments increase the chances of cybercrime during the outbreak, it is important for IS scholars to guide the organizations about how to secure their networks and data. By analyzing 185 COVID-19 related scam incidents, Naidoo (2020) found that cybercrimes are continually evolving in breadth, diversity and method of attack in response to changing situational factors.

\section{IT governance}

The pandemic has created an urgent need for widespread digital contact and tracing apps as the apps were significantly correlated with a reduction in the spread (Urbaczewski \& Lee, 2020). However, there are no universal solutions for the government to efficiently leverage these IT resources (Zilber \& Goodman, 2021) and a number of studies have explored this topic. The study by Riemer et al. (2020) shows that this digital solution works effectively only if adopted by the majority of the population which depends on immediate health risk, prior experience with pandemics, national culture, the role of government, trust in government and trust in technology. Trang et al. (2020) investigated the app specifications salient for mass acceptance by conducting a full-factorial experiment. 


\section{Issues in Information Systems}

Volume 22, Issue 4, pp. 93-109, 2021

Moreover, the rapid adoption of digital solutions for the track and trace throughout the population presents severe security and privacy concerns that limit implementation efficiency in turn (LeclercqVandelannoitte \& Aroles, 2020). The studies by Rowe (2020) and Rowe et al. (2020) present that the contact tracing apps could have failed in design and adoption due to the government underestimating the long-term concerns on the ethical or moral dilemmas of technology itself. Through a natural breaching experiment, these issues were further explored by Faraj et al. (2020) and their study revealed four important issues affecting the adoption of digital technology: uneven accessibility to digital infrastructures, the persistence of the legacy, unguided digitalization, and universal surveillance. The study by Janssen and van der Voort (2020) explores these aspects from the perspective of agility and adaptive governance and reflects their potential paradoxical nature in offering solutions.

\section{Digital divide}

Information and communication technology (ICT) is one of the most efficient tools to combat the disruption by the pandemic. However, ICTs may promote increasingly polarized, radicalized and even extremist viewpoints (Parra et al., 2021). The pandemic highlighted the digital divide issues and the need to bridge the digital divide. The long-term consequences of the digital divide are being explored by IS researchers. For example, Barnes (2020) highlights the key aspects of how technology can be used more effectively to create equality and improve well-being for certain demographic groups that are less technological. Zheng and Walsham (2021) focused on the feminist perspective to illustrate the roots of inequalities which deeply involve intersection and entanglement between digital technology, structural stratifications and social orders. Fletcher and Griffiths (2020) focus on different levels of digital maturity through a VUCA lens to reflect on how to cope with the impact of the pandemic. Pan, Cui, and Qian (2020) analyze the COVID-19 related digital divide through the lens of the Chinese family. Their study illuminates their information resourcing activities, information behavior adaptation activities and complexities faced by specific demographics in adapting to digital interaction. There is a solid need to mitigate negative aspects caused by unequal and unfair use of ICT to assist vulnerable populations, minorities and socio-economically disadvantaged groups affected by the pandemic. This line of research is promising and worthwhile for IS scholars to study (Marabelli et al., 2021).

\section{IS research direction in the post-pandemic period}

As the world begins to reopen from lockdown and move into an unprecedented state known as the 'new normal', it is necessary to reflect on what we have learned, revisit our fundamental assumptions and begin to chart a way forward (Sein, 2020; Henningsson et al., 2021). As some people believe the pandemic may permanently change the use of digital technologies, numerous IS scholars contribute their insights on challenges, impact and opportunities for information systems research. Traditional scientific hypotheses and societal order and control need to be reassessed (Doyle \& Conboy, 2020). Pan and Zhang (2020) highlight the related topics that future researchers could focus on and call for more research attention on tackling United Nations (UN) Sustainable Development Goals through developing the concept and practice of digital sustainability. The research outlined in Pee et al. (2021) posits a guideline on how future development should be accounted for from the perspective of design science research. Venkatesh (2020) presents a technology-focused research agenda and direction to solve people's life/home-related issues and the benefits of cross-border collaboration. He et al. (2021) focus on emerging technologies used to mitigate the threats of COVID-19 and relevant challenges related to technology design, development, and use. 


\section{Discussion}

By analyzing COVID-19 publications in the leading IS journals, we identified the key research themes, indicating the current trends in this area. The most popular research theme is related to digital transformation including research on telework, online education, organizations' resilience capability and business agility in the context of the pandemic. In addition, data-driven research including data analytics, data visualization, and the use of big data and AI to address the challenges posed by the pandemic is the second-most popular area for IS research. Other topics such as fake news, cybersecurity and digital divide are relatively less but are getting attention as the pandemic continues.

Various insights and lessons can be learned from these articles to help people, organizations and society to cope with the pandemic in the future. We share some of our thoughts as follows:

First, one of the promising future research agendas is to answer socio-technical questions such as: how can big data and AI transform the way we make decisions, especially for crisis management during a pandemic? How can decision-makers deal with uncertainty, urgency, and imperfect information? How to leverage user information while effectively protecting privacy? In order to address these questions, scholars and practitioners are recommended to consider the following lines of research:

- Studying people's behavior and responses to different ICT solutions. According to people's feedback and reflection, decision-makers need to better understand people's demands and concerns. Therefore, they could adjust their strategies to handle people's inquiries timely.

- Studying contextual factors affecting crisis response and management. The government not only needs to respond to the crisis in a timely manner but also needs to win public trust. Future initiatives are needed to enhance trust and reduce misinformation and polarization on social media and other internet platforms. Research on privacy protection, misinformation detection, opinion polarization is worthwhile.

- Studying digital privacy protection and related trade-offs. Policies, regulations and technologies need to be in place to enhance privacy protection with various technologies to ensure the wellbeing of users. This type of research is important for the development of privacy-preserving technologies.

Second, another important research agenda is related to the use of technologies. For example, how can information technologies be used efficiently to help organizations and humans transform to digital workspace; how to minimize the inequity digital divide and improve global wellbeing. Scholars need to understand the heterogeneous demographic characteristics. Different users may have other preferences for certain information technology depending on the context. Further research needs to find the nuances of user behavior with different technical solutions. Some interesting research questions are proposed as follows:

- Can collaborative learning methods mitigate negative psychological impacts on disadvantaged students?

- How to resolve the conflicts between organization and employee regarding their priority and preference for telework during and after the pandemic?

-What might be done to help people with disabilities and the elderly mitigate the impact of future pandemics on their physical and mental health, especially in lockdown situations?

- What steps are needed to get people together to achieve effective and secure data transfer among numerous health systems and platforms? 


\section{Issues in Information Systems}

Volume 22, Issue 4, pp. 93-109, 2021

Thirdly, another set of opportunities for the research community is to summarize generalizable theories and effective ways from this unprecedented pandemic in order to better combat future crises. Models including demographic, individual, and organizational variables can provide a broader understanding of factors that affect crisis handling and response in the pandemic context. Research on supporting disadvantaged groups of people also deserves more attention. To better understand the effect of different approaches to deal with crises, it often requires the long-term tracking of the individual technology solutions and analysis of massive amounts of time-series data. In addition, more theory-based research needs to be conducted to examine relevant variables determining the role of IS during the pandemic. Further research should use theory-based research models and collect primary data to explore the role of IS in mitigating the impact of a crisis like COVID-19 on diverse user groups and organizations.

In terms of practical implications, timely syntheses of IS researchers' work and contribution in the area of COVID-19 can help strengthen the role of the information systems discipline as an academic discipline and help practitioners and policymakers better understand the value of the socio-technical approach to solving a complex problem like the pandemic. A multidisciplinary team including technological, behavioral, sociological and organizational perspectives is needed to develop holistic solutions to tackle complicated challenges.

\section{Limitation and future directions}

There are several limitations to this study. First, this review confines data sources to the $14 \mathrm{~A}^{*}$ level IS journals. Although this is a common practice adopted for such research, the disadvantage is that this review couldn't reflect all quality papers published in the IS field on this topic. A more comprehensive review can be conducted by adding the latest articles published in conferences and IS-related articles in other disciplines. Secondly, we mainly focused on the content of the papers in our review and did not go into the details such as study methodologies, statistical approaches, sample sizes, population characteristics, geographic sites, and so on. Getting those details in future studies will enhance the diverse angle of the review. Thirdly, this review was completed by the end of May 2021 while the COVID-19 pandemic is still ongoing. Hence, this review does not reflect the currency of the COVID-19 research in the IS field. A living systematic review approach (Elliott et al., 2017) is needed to keep the review updated as new studies are being published.

\section{Conclusion}

In the context of an ongoing pandemic, it is vital to synthesize the existing knowledge and address knowledge gaps in the field. In order to understand what is known and done by IS researchers regarding the increasing number of publications on COVID-19, we did a systematic review of published articles with a focus on COVID-19 in 14 leading IS journals. An analysis of the articles published in the 14 leading IS journals on COVID-19 reveals six major research themes including (a) Digital transformation, (b) Data visualization and AI, (c) Infodemic and cybersecurity, (d) IT governance, (e) Digital divide, and (f) IS research direction in the post-pandemic period.

The increasing number of coronavirus literature in the IS field makes it difficult for scholars to keep up. We hope this review provides insights and thoughts for IS scholars and practitioners to evaluate possible opportunities for conducting research and development activities related to the pandemic, deepen research efforts in these topic areas, or expand existing research to help tackle challenges associated with COVID19 and future pandemics. As for further research, we hope to conduct a more comprehensive systematic literature review on all IS-related articles on COVID-19 including journal articles and conference papers 


\section{Issues in Information Systems}

Volume 22, Issue 4, pp. 93-109, 2021

and use approaches including text mining and topic modeling to identify additional or hidden knowledge, patterns and insights.

\section{References}

Adam, M., Werner, D., Wendt, C., \& Benlian, A. (2020). Containing COVID-19 through physical distancing: The impact of real-time crowding information. European Journal of Information Systems, 29(5), 595-607. https://doi.org/10/gj36mw

Ågerfalk, P. J., Conboy, K., \& Myers, M. D. (2020). Information systems in the age of pandemics: COVID-19 and beyond. European Journal of Information Systems, 29(3), 203-207

Barnes, S. J. (2020). Information management research and practice in the post-COVID-19 world. International Journal of Information Management, 55, 102175. https://doi.org/10.1016/j.ijinfomgt.2020.102175

Bunker, D. (2020). Who do you trust? The digital destruction of shared situational awareness and the COVID-19 infodemic. International Journal of Information Management, 55, 102201. https://doi.org/10/gg65f6

Carillo, K., Cachat-Rosset, G., Marsan, J., Saba, T., \& Klarsfeld, A. (2021). Adjusting to epidemicinduced telework: Empirical insights from teleworkers in France. European Journal of Information Systems, 30(1), 69-88. https://doi.org/10/ghf9s6

Carroll, N., \& Conboy, K. (2020). Normalising the "new normal": Changing tech-driven work practices under pandemic time pressure. International Journal of Information Management, 55, 102186.

Carugati, A., Mola, L., Plé, L., Lauwers, M., \& Giangreco, A. (2020). Exploitation and exploration of IT in times of pandemic: From dealing with emergency to institutionalising crisis practices. European Journal of Information Systems, 29(6), 762-777. https://doi.org/10/gj36mq

Chatterjee, S., Chakraborty, S., Fulk, H. K., \& Sarker, S. (2021). Building a compassionate workplace using information technology: Considerations for information systems research. International Journal of Information Management, 56, 102261. https://doi.org/10/gj36m7 


\section{Issues in Information Systems}

Volume 22, Issue 4, pp. 93-109, 2021

Coombs, C. (2020). Will COVID-19 be the tipping point for the Intelligent Automation of work? A review of the debate and implications for research. International Journal of Information Management, 55, 102182. https://doi.org/10/gg5j7h

De', R., Pandey, N., \& Pal, A. (2020). Impact of digital surge during Covid-19 pandemic: A viewpoint on research and practice. International Journal of Information Management, 55, 102171. https://doi.org/10.1016/j.ijinfomgt.2020.102171

Doyle, R., \& Conboy, K. (2020). The role of IS in the covid-19 pandemic: A liquid-modern perspective. International Journal of Information Management, 55, 102184. https://doi.org/10/ghc4rk

Elliott, J. H., Synnot, A., Turner, T., Simmonds, M., Akl, E. A., McDonald, S., ... \& Pearson, L. (2017). Living systematic review: 1. Introduction - the why, what, when, and how. Journal of clinical epidemiology, 91, 23-30.

Fahey, R. A., \& Hino, A. (2020). COVID-19, digital privacy, and the social limits on data-focused public health responses. International Journal of Information Management, 55, 102181. https://doi.org/10/gjhpsf

Faraj, S., Renno, W., \& Bhardwaj, A. (2021). Unto the breach: What the COVID-19 pandemic exposes about digitalization. Information and Organization, 31(1), 100337. https://doi.org/10/gj36nd

Fletcher, G., \& Griffiths, M. (2020). Digital transformation during a lockdown. International Journal of Information Management, 55, 102185. https://doi.org/10/ghjhpt

Glover, A. D. (2016). Publishing in the Top Journals of the ABDC Journal List: A Cross-Disciplinary Study.

Grover, V., \& Sabherwal, R. (2020). Making sense of the confusing mix of digitalization, pandemics and economics. International Journal of Information Management, 55, 102234. https://doi.org/10/gj36m3 


\section{Issues in Information Systems}

Volume 22, Issue 4, pp. 93-109, 2021

Hafermalz, E., \& Riemer, K. (2021). Productive and connected while working from home: What clientfacing remote workers can learn from telenurses about 'belonging through technology.' European Journal of Information Systems, 30(1), 89-99. https://doi.org/10/ghjdn7

He, W., Zhang, Z. (Justin), \& Li, W. (2021). Information technology solutions, challenges, and suggestions for tackling the COVID-19 pandemic. International Journal of Information Management, 57, 102287. https://doi.org/10/ghrh2z

Henningsson, S., Kettinger, W. J., Zhang, C., \& Vaidyanathan, N. (2021). Transformative rare events: Leveraging digital affordance actualisation. European Journal of Information Systems, 30(2), 137-156. https://doi.org/10/gj36m6

Iivari, N., Sharma, S., \& Ventä-Olkkonen, L. (2020). Digital transformation of everyday life - How COVID-19 pandemic transformed the basic education of the young generation and why information management research should care? International Journal of Information Management, 55, 102183. https://doi.org/10.1016/j.ijinfomgt.2020.102183

Laato, S., Islam, A. K. M. N., Islam, M. N., \& Whelan, E. (2020). What drives unverified information sharing and cyberchondria during the COVID-19 pandemic? European Journal of Information Systems, 29(3), 288-305. https://doi.org/10/gg8hnd

Leclercq-Vandelannoitte, A., \& Aroles, J. (2020). Does the end justify the means? Information systems and control society in the age of pandemics. European Journal of Information Systems, 29(6), 746-761. https://doi.org/10.1080/0960085X.2020.1820912

Leonardi, P. M., Woo, D., \& Barley, W. C. (2021). On the making of crystal balls: Five lessons about simulation modeling and the organization of work. Information and Organization, 31(1), 100339. https://doi.org/10/gj36nc

Lin, J., Li, L., Luo, X. (Robert), \& Benitez, J. (2020). How do agribusinesses thrive through complexity? The pivotal role of e-commerce capability and business agility. Decision Support Systems, 135, 113342. https://doi.org/10/gg2fvs 


\section{Issues in Information Systems}

Volume 22, Issue 4, pp. 93-109, 2021

Majchrzak, A., \& Shepherd, D. A. (2021). Can digital innovations help reduce suffering? A crowd-based digital innovation framework of compassion venturing. Information and Organization, 31(1), 100338. https://doi.org/10.1016/j.infoandorg.2021.100338

Marabelli, M., Vaast, E., \& Li, J. L. (2021). Preventing the digital scars of COVID-19. European Journal of Information Systems, 30(2), 176-192. https://doi.org/10/gjjp7v

Mirbabaie, M., Bunker, D., Stieglitz, S., Marx, J., \& Ehnis, C. (2020). Social media in times of crisis: Learning from Hurricane Harvey for the coronavirus disease 2019 pandemic response. Journal of Information Technology, 35(3), 195-213. https://doi.org/10.1177/0268396220929258

Naidoo, R. (2020). A multi-level influence model of COVID-19 themed cybercrime. European Journal of Information Systems, 29(3), 306-321. https://doi.org/10/gjv8jw

Oliphant, T. (2021). Emerging (information) realities and epistemic injustice. Journal of the Association for Information Science and Technology, asi.24461. https://doi.org/10/gjmmzj

O’Leary, D. E. (2020). Evolving information systems and technology research issues for COVID-19 and other pandemics. Journal of Organizational Computing and Electronic Commerce, 30(1), 1-8.

Pan, S. L., Cui, M., \& Qian, J. (2020). Information resource orchestration during the COVID-19 pandemic: A study of community lockdowns in China. International Journal of Information Management, 54, 102143. https://doi.org/10/ghfbtq

Pan, S. L., \& Zhang, S. (2020). From fighting COVID-19 pandemic to tackling sustainable development goals: An opportunity for responsible information systems research. International Journal of Information Management, 55, 102196. https://doi.org/10.1016/j.jinfomgt.2020.102196

Papadopoulos, T., Baltas, K. N., \& Balta, M. E. (2020). The use of digital technologies by small and medium enterprises during COVID-19: Implications for theory and practice. International Journal of Information Management, 55, 102192. https://doi.org/10/fgrv 


\section{Issues in Information Systems}

Volume 22, Issue 4, pp. 93-109, 2021

Papagiannidis, S., Harris, J., \& Morton, D. (2020). WHO led the digital transformation of your company? A reflection of IT related challenges during the pandemic. International Journal of Information Management, 55, 102166. https://doi.org/10/gj36m2

Parra, C. M., Gupta, M., \& Mikalef, P. (2021). Information and communication technologies (ICT)enabled severe moral communities and how the (Covid19) pandemic might bring new ones. International Journal of Information Management, 57, 102271.

https://doi.org/10.1016/j.ijinfomgt.2020.102271

Pee, L. G., Pan, S. L., Wang, J., \& Wu, J. (2021). Designing for the future in the age of pandemics: A future-ready design research (FRDR) process. European Journal of Information Systems, 30(2), 157-175. https://doi.org/10.1080/0960085X.2020.1863751

Pietz, J., McCoy, S., \& Wilck, J. H. (2020). Chasing John Snow: Data analytics in the COVID-19 era. European Journal of Information Systems, 29(4), 388-404. https://doi.org/10/gg559j

Prommegger, B., Bennett Thatcher, J., Wiesche, M., \& Krcmar, H. (2021). When your data has COVID19: How the changing context disrupts data collection and what to do about it. European Journal of Information Systems, 30(1), 100-118. https://doi.org/10/gj36m4

Rao, H. R., Vemprala, N., Akello, P., \& Valecha, R. (2020). Retweets of officials' alarming vs reassuring messages during the COVID-19 pandemic: Implications for crisis management. International Journal of Information Management, 55, 102187. https://doi.org/10/gg4sq3

Recker, J. (2021). Improving the state-tracking ability of corona dashboards. European Journal of Information Systems, 1-20. https://doi.org/10/gj7hwr

Riemer, K., Ciriello, R., Peter, S., \& Schlagwein, D. (2020). Digital contact-tracing adoption in the COVID-19 pandemic: IT governance for collective action at the societal level. European Journal of Information Systems, 29(6), 731-745. https://doi.org/10/gj36mx 


\section{Issues in Information Systems}

Volume 22, Issue 4, pp. 93-109, 2021

Rowe, F. (2020). Contact tracing apps and values dilemmas: A privacy paradox in a neoliberal world. In INTERNATIONAL JOURNAL OF INFORMATION MANAGEMENT (Vol. 55). ELSEVIER SCI LTD. https://doi.org/10.1016/j.ijinfomgt.2020.102178

Rowe, F., Ngwenyama, O., \& Richet, J.-L. (2020). Contact-tracing apps and alienation in the age of COVID-19. European Journal of Information Systems, 29(5), 545-562. https://doi.org/10/ghh8hf

Sakurai, M., \& Chughtai, H. (2020). Resilience against crises: COVID-19 and lessons from natural disasters. European Journal of Information Systems, 29(5), 585-594. https://doi.org/10/ghqw24

Sein, M. K. (2020). The serendipitous impact of COVID-19 pandemic: A rare opportunity for research and practice. International Journal of Information Management, 55, 102164. https://doi.org/10/gj36mz

Shirish, A., Srivastava, S. C., \& Chandra, S. (2021). Impact of mobile connectivity and freedom on fake news propensity during the COVID-19 pandemic: A cross-country empirical examination. European Journal of Information Systems, 30(3), 322-341. https://doi.org/10.1080/0960085X.2021.1886614

Sipior, J. C. (2020). Considerations for development and use of AI in response to COVID-19. International Journal of Information Management, 55, 102170. https://doi.org/10/ghjhhv

Tranfield, D., Denyer, D., \& Smart, P. (2003). Towards a methodology for developing evidence-informed management knowledge by means of systematic review. British Journal of Management, 14(3), $207-222$.

Trang, S., Trenz, M., Weiger, W. H., Tarafdar, M., \& Cheung, C. M. K. (2020). One app to trace them all? Examining app specifications for mass acceptance of contact-tracing apps. European Journal of Information Systems, 29(4), 415-428. https://doi.org/10/gh4vz4

Urbaczewski, A., \& Lee, Y. J. (2020). Information Technology and the pandemic: A preliminary multinational analysis of the impact of mobile tracking technology on the COVID-19 contagion control. European Journal of Information Systems, 29(4), 405-414. https://doi.org/10/gg7tpb 


\section{Issues in Information Systems}

Volume 22, Issue 4, pp. 93-109, 2021

Venkatesh, V. (2020). Impacts of COVID-19: A research agenda to support people in their fight. International Journal of Information Management, 55, 102197. https://doi.org/10/gg5kfv

Waizenegger, L., McKenna, B., Cai, W., \& Bendz, T. (2020). An affordance perspective of team collaboration and enforced working from home during COVID-19. European Journal of Information Systems, 29(4), 429-442.

Webster, J., \& Watson, R. T. (2020). Analyzing the Past to Prepare for the Future: Writing a Literature Review. 12

Westmattelmann, D., Grotenhermen, J.-G., Sprenger, M., \& Schewe, G. (n.d.). The show must go onvirtualisation of sport events during the COVID-19 pandemic. In EUROPEAN JOURNAL OF INFORMATION SYSTEMS. TAYLOR \& FRANCIS LTD.

https://doi.org/10.1080/0960085X.2020.1850186

Whillans, A., Perlow, L., \& Turek, A. (2021). Experimenting during the shift to virtual team work: Learnings from how teams adapted their activities during the COVID-19 pandemic. Information and Organization, 31(1), 100343. https://doi.org/10/gj36nb

Zheng, Y., \& Walsham, G. (2021). Inequality of what? An intersectional approach to digital inequality under Covid-19. Information and Organization, 31(1), 100341. https://doi.org/10/gj36m9

Zilber, T. B., \& Goodman, Y. C. (2021). Technology in the time of corona: A critical institutional reading. Information and Organization, 31(1), 100342. https://doi.org/10/gj36m8 